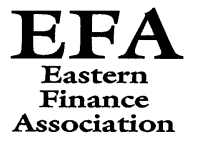

The Financial Review 40 (2005) 1-9

The Financial Review

\title{
Reflections on the Efficient Market Hypothesis: 30 Years Later
}

\author{
Burton G. Malkiel* \\ Princeton University
}

\begin{abstract}
In recent years financial economists have increasingly questioned the efficient market hypothesis. But surely if market prices were often irrational and if market returns were as predictable as some critics have claimed, then professionally managed investment funds should easily be able to outdistance a passive index fund. This paper shows that professional investment managers, both in The U.S. and abroad, do not outperform their index benchmarks and provides evidence that by and large market prices do seem to reflect all available information.
\end{abstract}

Keywords: efficient markets, stock market predictability

JEL Classifications: G12, G14

I have been an advocate of the efficient market hypothesis for over 30 years. In my view, equity prices adjust to new information without delay and, as a result, no arbitrage opportunities exist that would allow investors to achieve above-average returns without accepting above-average risk. This hypothesis is associated with the view that stock market price movements approximate those of a random walk. If new information develops randomly, then so will market prices, making the stock market unpredictable apart from its long-run uptrend. I suggested, largely in jest, that

\footnotetext{
*Corresponding author: Chemical Bank Chairman's Professor of Economics, Princeton University, Princeton University_-Bendheim Center for Finance; 26 Prospect Avenue; Princeton, NJ 08540; United States; Phone: (609) 258-6445; Fax: (609) 258-0771; E-mail: bmalkiel@princeton.edu
}

This paper was presented to the 2004 Meetings of the Eastern Finance Association in Mystic, Connecticut. 
a blindfolded chimpanzee throwing darts at the stock pages could select a portfolio that would do as well as the experts. ${ }^{1}$ In fact, the correct analogy is to throw a towel over the stock pages and simply buy an index fund, which buys and holds all the stocks making up a broad stock-market index.

In recent years, many financial economists have come to question the efficient market hypothesis. At least ex-post, there seem to be several instances where market prices failed to reflect available information. ${ }^{2}$ Moreover, periods of large-scale irrationality, such as the technology-internet "bubble" of the late 1990s extending into early 2000 , have convinced many analysts that the efficient market hypothesis should be rejected. ${ }^{3}$ In addition, financial econometricians have suggested that stock prices are, to a significant extent, predictable on the basis either of past returns or of certain valuation metrics such as dividend yields and price-earning ratios. ${ }^{4}$

Although it is possible to cast doubt on the statistical robustness of many of the predictable patterns that have been suggested, ${ }^{5}$ my skepticism is based on somewhat different evidence. Surely, if market prices often failed to reflect rational estimates of the prospects of companies, and if markets consistently overreacted (or under-reacted) to underlying conditions, then professional investors, who are richly incentivized to outperform passive investors, should be able to produce excess returns. For me, the strongest evidence suggesting that markets are generally quite efficient is that professional investors do not beat the market. Indeed, the evidence accumulated over the past 30-plus years makes me more convinced than ever that our stock markets are remarkably efficient at adjusting correctly to new information. And I am increasingly convinced that the best investment advice for both individual and institutional equity investors is to buy a low-cost broad-based index fund that holds all the stocks comprising the market portfolio. If prices were often irrational and if market returns were as predictable as some critics of the efficient market hypothesis believe, than surely actively managed investment funds should easily be able to outdistance a passive index fund that simply buys and holds the market portfolio.

\section{Returns from actively managed mutual funds}

Mutual funds are required to make their results public and, as a consequence, we have excellent data available from Lipper Analytical Services as well as from other

\footnotetext{
${ }^{1}$ See Burton G. Malkiel, A Random Walk Down Wall Street, 1st Edition, New York, W.W. Norton, 1973.

${ }^{2}$ One celebrated example during the late 1990s is when 3Com spun off five percent of the Palm shares it owned. Based on the market prices of Palm, the $95 \%$ of Palm still owned by 3Com was worth more than the total capitalization of the parent company.

${ }^{3}$ See, for example, Robert Shiller, Irrational Exuberance, Princeton, Princeton University Press, 2000.

${ }^{4}$ See, for example, Lo and MacKinlay (1999), Campbell and Shiller (1988a,b), Fama and French (1988) and DeBondt and Thaler (1995).
}

${ }^{5}$ See, for example, Fama (1998), and Malkiel (2003). 
Table 1

Percent of large capitalization equity funds outperformed by index ending December 31, 2003

\begin{tabular}{lccccc}
\hline & \multicolumn{5}{c}{ Holding period } \\
\cline { 2 - 6 } & 1 Year & 3 Years & 5 Years & 10 Years & 20 Years \\
\hline S\&P 500 versus large cap equity funds & $73 \%$ & $72 \%$ & $63 \%$ & $86 \%$ & $90 \%$ \\
\hline
\end{tabular}

Source: Lipper.

Table 2

Index funds tend to outperform by two percentage points. Comparison of returns: Average equity fund versus indexes

\begin{tabular}{lcc}
\hline & 10 Years to 12/31/03 & 20 Years to 12/31/03 \\
\hline S\&P 500 index & $10.99 \%$ & $12.78 \%$ \\
Average equity fund* & $8.47 \%$ & $10.54 \%$ \\
S\&P 500 advantage (percentage points) & 2.52 & 2.24 \\
\hline
\end{tabular}

Source: Lipper, Wilshire, \& the Vanguard Group.

* Consists of all Lipper equity categories.

data providers. Analysis of these data shows clearly that actively managed mutual funds do not outperform comparable benchmark indexes.

Table 1 indicates that during the year ended December 31, 2003, close to three quarters of the mutual funds holding large capitalization stocks were outperformed by the (large capitalization) Standard and Poor's 500 stock index. Results are similar for other one-year period. When returns are measured over periods of 10 years or longer, over $80 \%$ of active managers are outperformed by the index.

Table 2 presents data for all Lipper categories of equity mutual funds. The average (median) fund is compared with the Vanguard (S\&P) 500 Index Fund. Both the actively managed and the index fund returns are measured after expenses. We see that the typical actively managed fund underperforms the index fund by over 200 basis points.

A large return differential may appear surprising. It must be the case that all investors earn the market return before expenses, because all stocks must be held by someone. Therefore, investing must be a zero sum game with those investors who underperform the market balanced by other investors who achieve superior returns. Why, then, does the average active manager underperform by such a substantial amount? The answer is expenses. The typical active mutual fund has an expense ratio of just less than 150 basis points. Index funds can be run with minimal expense ratios less than 20 basis points, even for small individual investors. In addition, active managers turn over their portfolio_-often as much as $100 \%$ each year. Trading entails additional expenses from brokerage costs, bid-asked spreads, and market impact. The underperformance of active managers relative to the market index can be fully explained by these extra costs. 


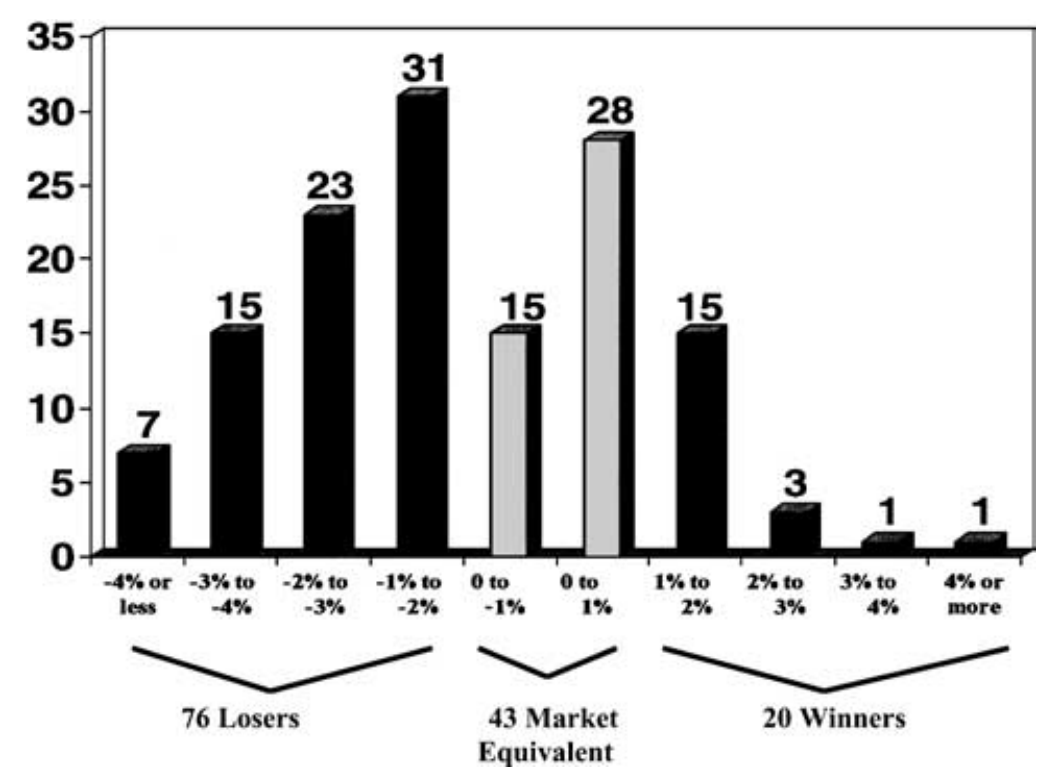

Figure 1

The odds of success: Returns of surviving mutual funds 1/1970-12/2003

The performance figures for active managers look even worse when measured over periods of 30 years or more. In 1970, there were 355 general equity funds. Only 139 survived through December 31, 2003. All we can measure over the entire period are the returns of the survivors. We should note, however, that the record of the nonsurvivors up to the time of their demise is substantially worse than the record of the survivors. It is difficult to sell a mutual fund with a particularly poor record. Thus, mutual fund complexes tend to merge poorly performing funds into better performing ones in order to eliminate the record of funds with poor performance. As a consequence, the data shown in Figure 1 are biased upwards. What they show, however, is quite unfavorable to active managers. The weight of the distribution is overwhelmingly skewed towards underperformance. Indeed, one can count on the fingers of one hand the number of funds that beat the market by $2 \%$ points or more over the 34-year period.

Although it is true that in any period there are some active managers who do achieve returns higher than the index, it is not possible to tell in advance who they will be. There is not sufficient persistence in performance to be able to chose winning managers by an examination of their past records. The 10 best actively managed funds during the 1960s achieved rates of return almost double that of the index but those same funds underperformed the index during the decade of the 1970s. Similarly, the best funds of the 1970s underperformed during the 1980s and the winners of the 1980s achieved below average returns during the 1990s. 
Table 3

The inconsistency of mutual fund performance

\begin{tabular}{lccc}
\hline & 4 Years & 4 Years & \\
& $12 / 31 / 1995$ & $12 / 31 / 1999$ & $1999-2003$ Rank \\
& $12 / 31 / 1999$ & $12 / 31 / 2003$ & (710 total funds*) \\
Fund name & Annual tot return & Annual tot return & 681 \\
\hline RS Inv: emerg gr & 51.09 & -16.83 & 692 \\
Janus twenty & 47.56 & -17.84 & 705 \\
PBHG: sel growth: PBHG & 43.55 & -21.28 & 671 \\
Janus mercury & 42.23 & -15.54 & 379 \\
Fidelity new milliennium & 42.23 & -4.09 & 707 \\
Fidelity aggr grow & 41.63 & -25.89 & 668 \\
Van Kampen emerg gro; A & 40.77 & -15.49 & 680 \\
WM: growth; A & 40.71 & -16.81 & 675 \\
Van Kampen emerg gro; B & 39.68 & -16.14 & 703 \\
Janus enterprise & 38.43 & -20.15 & 586 \\
Morg stan inst: MC Gr; I & 38.25 & -10.44 & 654 \\
Janus venture & 37.88 & -14.23 & 682 \\
IDEX: Jan growth; T & 37.57 & -16.84 & 258 \\
Legg Mason value Tr; Prm & 37.35 & -0.50 & 687 \\
IDEX: Jan growth; A & 37.29 & -17.23 & 605 \\
MFS mass inv gro; A & 37.12 & -11.53 & 708 \\
Morg stan spec gr; B & 36.69 & -26.76 & 496 \\
Janus growth and income & 36.39 & -7.18 & 660 \\
Vanguard growth equity & 35.00 & -14.51 & 633 \\
Fidelity OTC & 34.72 & -12.77 & \\
Average-top 20 & 39.81 & -15.10 & -5.34 \\
S\&P 500 index & 26.39 & -5.41 & \\
Vanguard 500 index fund & 26.35 & & \\
\hline & & & \\
& & &
\end{tabular}

${ }^{*}$ Group includes General Equity funds with more than $\$ 100$ million in assets as of 12/31/1995.

Table 3 presents a particularly dramatic illustration of the inconsistency of performance. The table lists the top 20 equity mutual funds in terms of returns achieved during the period from January 1, 1996 to December 31, 1999. These funds earned returns $50 \%$ higher than an index fund during those four years. The portfolio managers of these funds were written up in the financial press as investment geniuses and interviewed admiringly on CNBC and other TV channels. Money flowed into these funds in abundance. But investors who bought these "superior" funds were badly disappointed in the returns during the four years ending December 31, 2003. While the stock market as a whole suffered negative returns during the period, these funds generated negative returns almost three times worse than the market as a whole.

Past performance does not predict future returns. The ratings of professional investment services do no better. Morningstar provides an excellent information service for investors showing the past returns, expense ratios, risk levels, and considerable additional information regarding mutual funds. The service also provides a rating for each fund with four and five star ratings indicating those funds favored for 


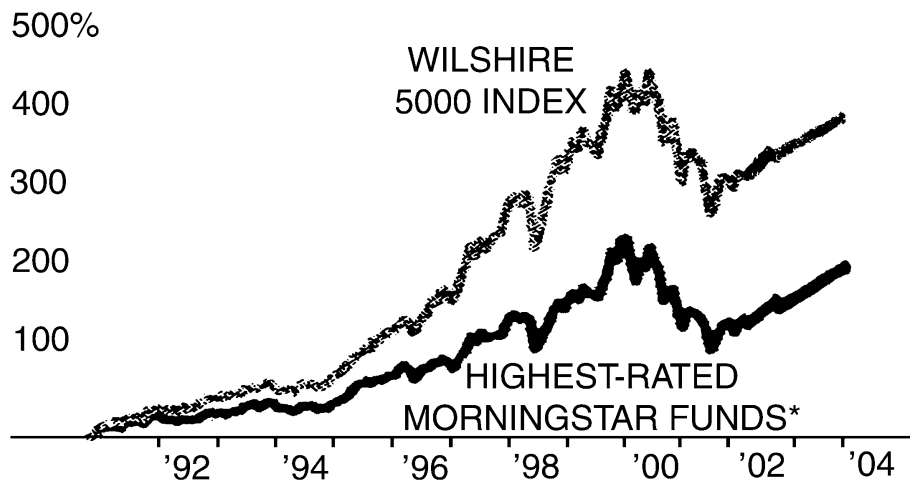

Figure 2

Morningstar 4 and 5 star funds versus the Wilshire 5000 index

* Based on equal investment in 55 funds, after expenses, loads and redemption fees. Source: Hulbert Financial Digest.

purchase. Unfortunately, while highly starred Michelin Guide restaurants guarantee the diner an excellent meal, four, and five star Morningstar ratings do not provide mutual fund investors with above-average returns. As Figure 2 shows, the highest-rated Morningstar funds substantially underperform the broad Wilshire 5000 stock-market index.

Index funds tend to outperform actively managed funds in international as well as in domestic markets. Figure 3 presents a comparison of actively managed European equity funds compared with the Morgan Stanley Capital International (MSCI) Europe stock market index. While in many individual years, $50 \%$ or more of the active managers do beat the index, the longer-term results confirm our findings for the United States. Over a 10-year period ending December 31, 2002, over $80 \%$ of the actively managed funds underperformed the index. Figure 4 presents a 10 -year performance distribution for European active managers similar to the comparison shown in Figure 1. Again, we see that over $80 \%$ of the active managers do worse than the index and only four managers were able to beat the index by 400 basis points or more.

Figure 5 examines the returns of actively managed global funds. The funds are compared with the MSCI World Equity Index. Again, we see that over the 10-year period ending December 31, 2002, 80\% of the active managers were outperformed by the index. Data are also available showing that small-capitalization active equity managers tend to be outperformed by a Russell 2000 small-cap benchmark index, and active emerging-market managers are unable to beat the MSCI emerging-market index. Even in markets that are undoubtedly less efficient than the large-capitalization U.S. market, active management does not win out. These results are likely to be explained in part because of the inefficiencies in the trading markets for small-cap and emerging-market stocks. Bid-asked spreads tend to be wide, price-impact costs 


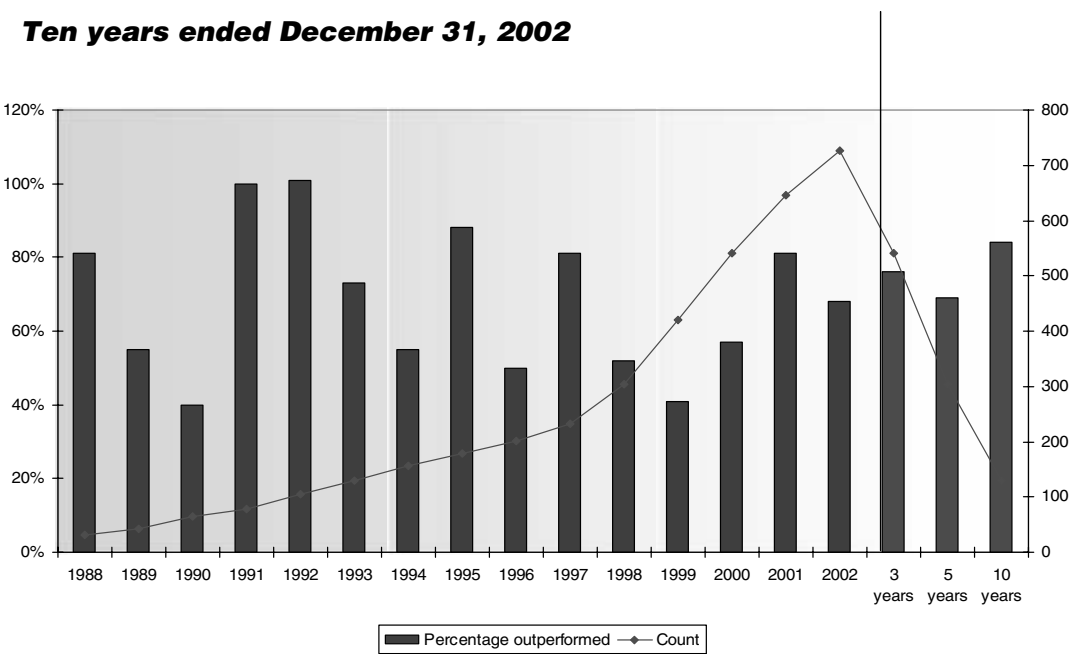

Figure 3

European equity managers outperformed by MSCI Europe index

Source: Standard \& Poor's Funds Service and Vanguard Investment Europe S.A.

Universe: European Equity Funds registered in Austria, Belgium, France, The Netherlands, Offshore, Luxembourg, UK, Germany, and Switzerland.

Ten Years Ended December 31, 2002

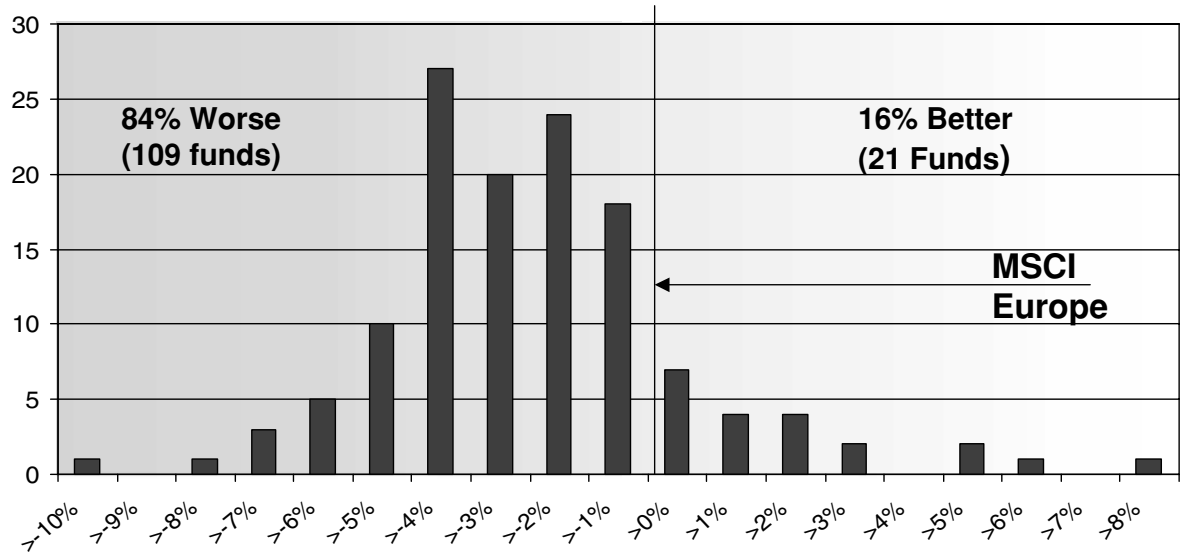

Figure 4

European equity managers compared with MSCI Europe index

Source: Standard \& Poor's Funds Service and Vanguard Investment Europe S.A.

Universe: European Equity Funds registered in Austria, Belgium, France, The Netherlands, Offshore, Luxembourg, UK, Germany, and Switzerland. All returns are in euros ex ECU net of fees. 
Ten Years Ended December 31, 2002

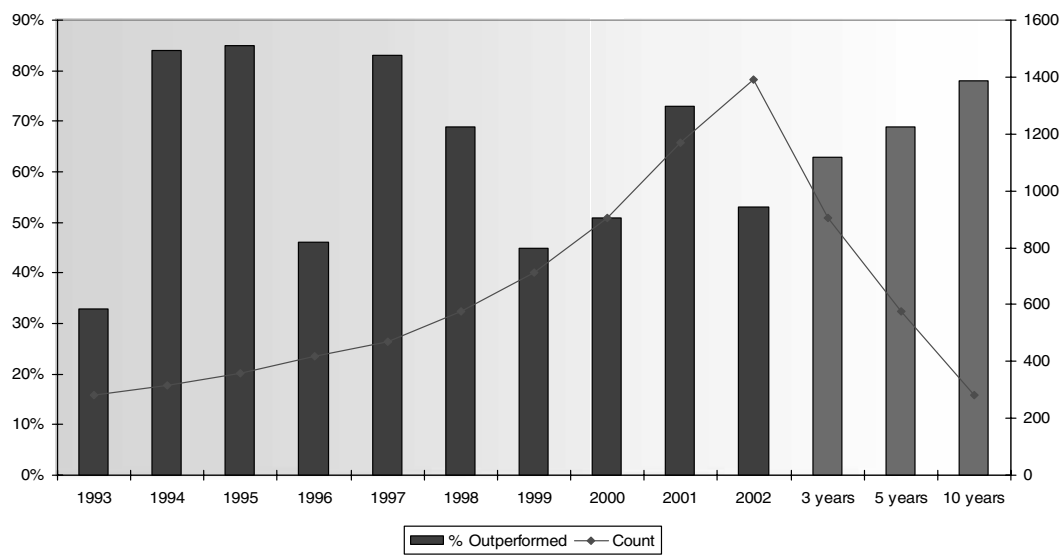

Figure 5

European global equity managers compared with the MSCI world equity index

Source: Standard \& Poor's Funds Service and Vanguard Investment Europe S.A.

Universe: European Equity Funds registered in Austria, Belgium, France, The Netherlands, Offshore, Luxembourg, UK, Portugal, Germany, and Switzerland. All returns are in USD net of fees.

tend to be large, and, in emerging markets, a variety of transfer taxes tend to make trading far more costly.

\section{Concluding comments}

The evidence is overwhelming that active equity management is, in the words of Ellis (1998), a “loser's game." Switching from security to security accomplishes nothing but to increase transactions costs and harm performance. Thus, even if markets are less than fully efficient, indexing is likely to produce higher rates of return than active portfolio management. Both individual and institutional investors will be well served to employ indexing for, at the very least, the core of their equity portfolio.

Even the legendary Benjamin Graham, in an interview given shortly before he died, was quoted as saying:

"I am no longer an advocate of elaborate techniques of security analysis in order to find superior value opportunities. This was a rewarding activity, say, 40 years ago, when Graham and Dodd was first published; but the situation has changed.... [Today] I doubt whether such extensive efforts will generate sufficiently superior selections to justify their cost.... I'm on the side of the 'efficient market' school of thought." 6

\footnotetext{
${ }^{6}$ Benjamin Graham as quoted in the Financial Analysts Journal, 1976.
} 
And the most successful modern-day investor, Warren Buffett, who has beaten the market over a prolonged period of time, sums up the advice in this paper with characteristic wisdom:

"Most investors, both institutional and individual, will find that the best way to own common stocks (shares') is through an index fund that charges minimal fees. Those following this path are sure to beat the net results (after fees and expenses) of the great majority of investment professionals."

\section{References}

Buffett, W., 1996. Annual Report, Berkshire Hathaway.

Campbell, J.Y. and R.J. Shiller, 1988a. Stock prices, earnings, and expected dividends, Journal of Finance 43, 661-676.

Campbell, J.Y. and R.J. Shiller, 1988b. Valuation ratios and the long-run stock market outlook, Journal of Portfolio Management 24, 11-26.

DeBondt, W.F.M. and R. Thaler, 1995. Financial decision-making in markets and firms: A behavioral perspective, in: Jarrow R. et al., eds., Handbook in OR \& MS, Vol. 9, Chapter 13 (Elsevier Science, New York).

Ellis, C., 1998. Winning the Loser's Game, (McGraw-Hill, New York).

Fama, E., 1998. Market efficiency, long-term returns, and behavioral finance, Journal of Financial Economics 49, 283-306.

Fama, E. and K. French, 1988. Permanent and temporary components of stock prices, Journal of Political Economy 96, 246-273.

Graham, B., 1976. A conversation with Benjamin Graham, Journal of Financial Analysts 32, $20-23$.

Lo, A.W. and A.C. MacKinlay, 1999. A Non-Random Walk Down Wall Street (Princeton University Press, Princeton).

Malkiel, B.G., 1973. A Random Walk Down Wall Street (W.W. Norton \& Co., New York).

Malkiel, B.G., 2003. The efficient market hypothesis and its critics, Journal of Economic Perspectives 17 , 59-82.

\footnotetext{
${ }^{7}$ Warren Buffett-Berkshire Hathaway Annual Report, 1996.
} 